\title{
Partial nodular transformation of the caudate lobe of the liver presenting with ascites
}

\author{
M. S. FLETCHER \\ F.R.C.S.*
}

\author{
D. G. D. WIGHT \\ M.A., M.R.C.Path.
}

\author{
Addenbrooke's Hospital, Cambridge
}

\begin{abstract}
Summary
Partial nodular transformation is a rare condition which affects the perihilar portion of the liver and may cause chronic portal hypertension. This case report describes an elderly woman in whom the condition was confined to the caudate lobe, which had become greatly enlarged and, by external compression of the portal vein at the hilum of the liver, had caused portal vein thrombosis and subsequent acute ascites.
\end{abstract}

\section{Introduction}

Many causes of extra-hepatic portal vein thrombosis have been implicated in adults, although a large group often remain idiopathic (Thompson and Sherlock, 1964; Turcotte and Child, 1972). Minor variations in size and configuration of both lobes of the liver are common but major anomalies are rare (Pujari and Deodhare, 1976). The caudate lobe may become enlarged in the Budd-Chiari syndrome (Tavill et al., 1975) but massive enlargement confined to the caudate lobe and causing marked compression and thrombosis of the extrahepatic portal vein has not previously been described.

\section{Case report}

A previously fit 90 -year-old spinster was admitted with a 3-day history of progressively severe lower abdominal pain, loose stools, anorexia and increasing abdominal swelling. On examination she was dehydrated and had marked abdominal distension due to ascites. There was considerable lower abdominal tenderness and bowel sounds were scanty. There were no stigmata of chronic liver disease nor other signs of cardiac failure. Investigations on admission were as follows: $\mathrm{Hb}, 13.3 \mathrm{~g} / \mathrm{dl}$; WCC, $8 \times 10^{9} / 1$; PCV, 0.394 ; ESR, $6 \mathrm{~mm}$ in the first hr (Westergren); urea and electrolytes normal; total proteins, $57 \mathrm{~g} / \mathrm{l}$; albumin, $31 \mathrm{~g} / \mathrm{l}$; serum bilirubin, $22 \mu \mathrm{mol} / \mathrm{l}$; alkaline phosphatase, 62 i.u./l. Urine contained no albumin. Chest X-ray showed some left basal shadowing, and abdominal X-rays

* Present address: Department of Surgery, King's College Hospital, Denmark Hill, London SE5. suggested the presence of free fluid with several $\overrightarrow{\vec{\omega}}$ small bowel fluid levels.

After rehydration with i.v. fluid and a period of observation, the abdominal pain became more severe, rebound tenderness was noted and bowel sounds were absent. At laparotomy 3 litres of clear, pale yellow $\mathcal{G}$ peritoneal fluid were found and there was venous + engorgement of the small intestine, which was $\vec{N}$ moderately dilated throughout its length. The liver ${ }^{\circ}$ was small and a large smooth mass approximately $12 \times 9 \times 8 \mathrm{~cm}$ was found to project forwards and $\overrightarrow{>}$ downwards from the caudate lobe, causing marked compression of the portal vein just proximal to its bifurcation (Fig. 1). Proximal to this the vein wos $\vec{\bullet}$ dilated and thrombosed. Several biopsies weeg taken from this mass, but in view of the patient age and general condition no further procedure w⿳亠口冋阝 undertaken. Postoperatively, in spite of diuretic therapy and sodium restriction the patient's condition deteriorated and she died on the 10th post- $\mathbb{Q}$ operative day.

At post-mortem, although the liver weighed only $\frac{\overrightarrow{\vec{\partial}}}{3}$ $940 \mathrm{~g}$ (total body weight $58 \mathrm{~kg}$ ), the caudate lobe was grossly enlarged and had compressed the extra-hepatic portal vein at its origin from the superior mesenteric and splenic tributaries. On 3 section this resembled the remainder of the liver and had no clear boundary or capsule. There was 3 . no other evidence of portal hypertension and the $\delta$ inferior vena cava and hepatic veins were normal. The spleen weighed $168 \mathrm{~g}$.

Histologically, the appearances were somewhat variable. Both in the enlarged caudate lobe and in the remainder of the liver there was evidence of chronic passive congestion with mild centrilobular 0 sinusoidal dilatation and hepatocyte atrophy. In $N$ addition within the caudate lobe there was a striking $\underset{\mathrm{N}}{\mathrm{N}}$ nodularity which had not been apparent macro- $O$ scopically. There was nodular hyperplasia of the liver cells, largely centred upon portal triads, and $\stackrel{0}{\odot}$ here most of the liver cell plates were 2 or more cells $\stackrel{\oplus}{\longrightarrow}$ thick. These nodules had a pushing margin apparently compressing the adjacent atrophied centri- 0 lobular cells (Figs 2 and 3). Portal tracts and efferent $\stackrel{\mathbb{\mathrm { D }}}{\mathbb{\mathrm { O }}}$ 


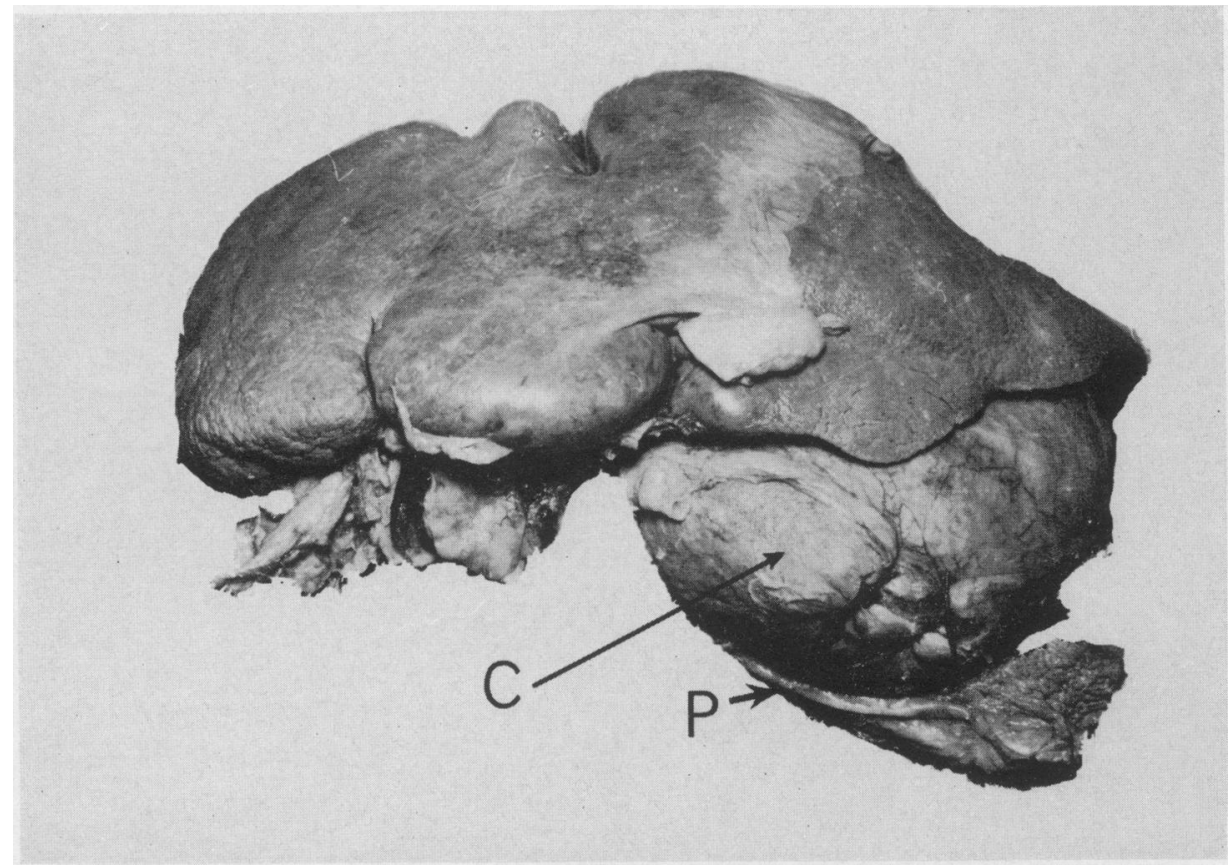

Fig. 1. Post-mortem photograph of liver showing a massively enlarged caudate lobe (C) causing marked compression of the portal vein $(\mathrm{P})$.

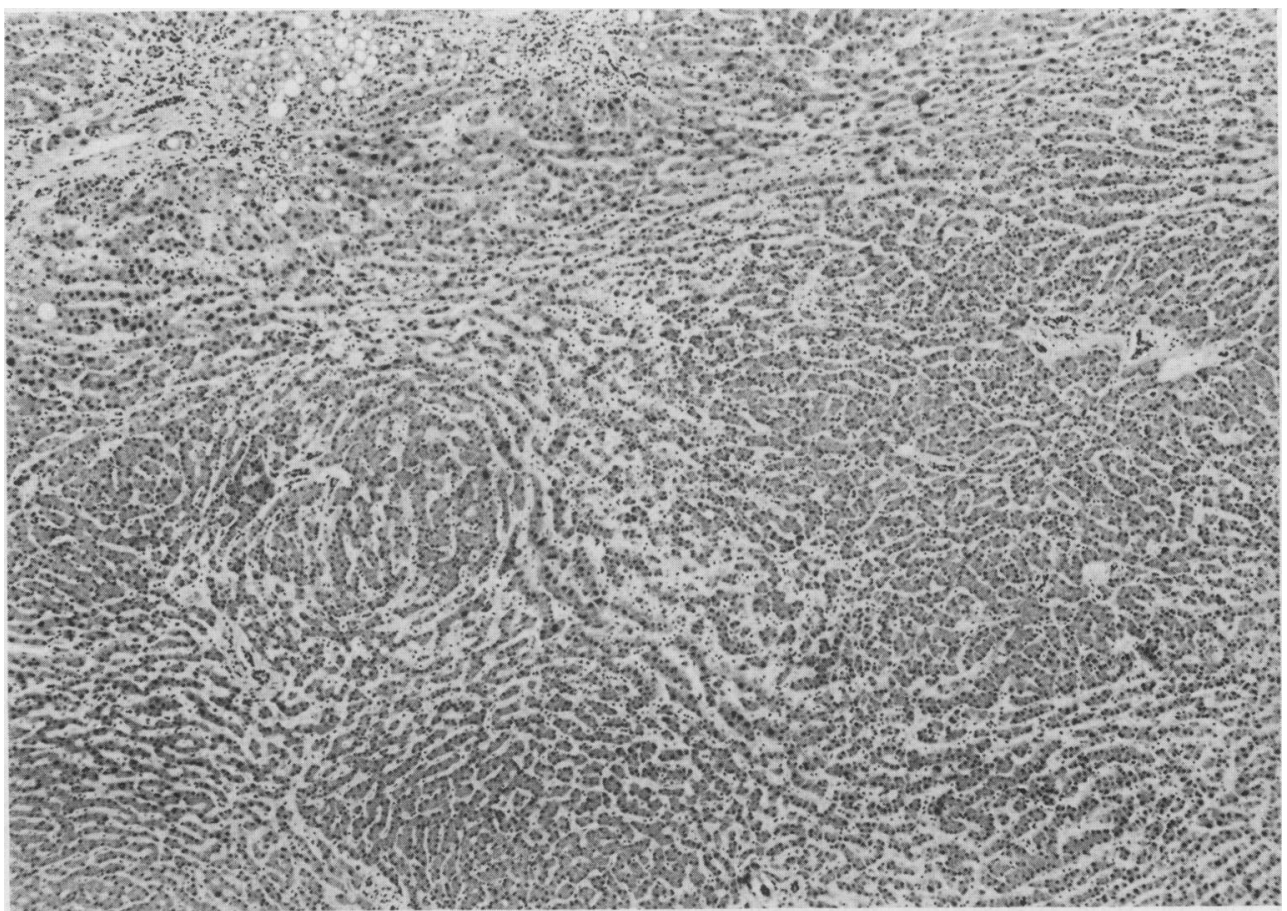

Fig. 2. Lower power view of the caudate lobe showing marked nodularity of the liver, but a complete absence of fibrosis $(\mathrm{HE}, \times 40)$. 


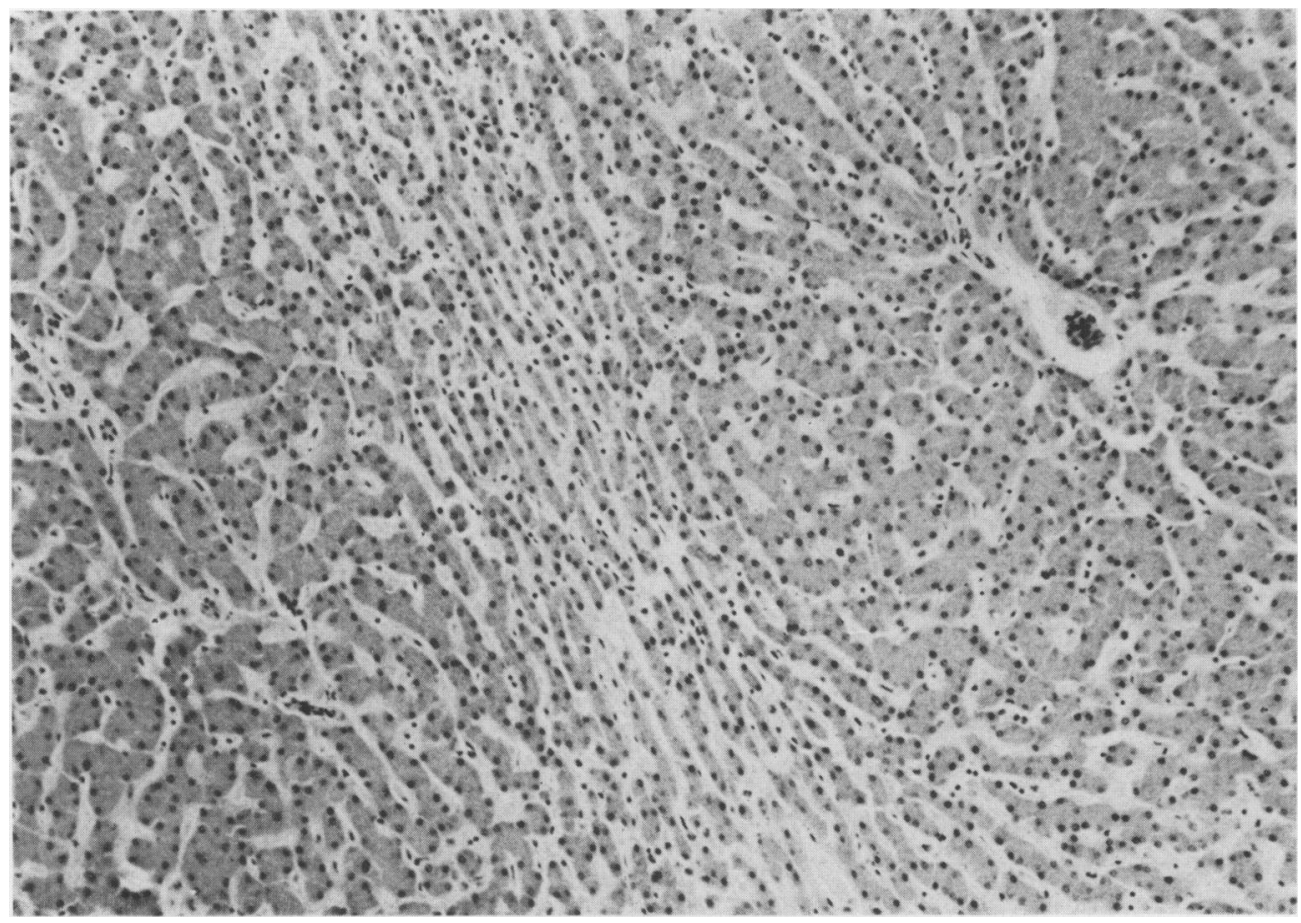

FIg. 3. Higher magnification of the caudate lobe showing thinning of liver cell plates in the periportal regions with compression of the thinned hepatocytes in the centrilobular region (centre of photomicrograph) $(\mathrm{HE}, \times 102 \cdot 5)$.

veins retained their normal relationships and there was no evidence of increased fibrosis and no bile duct proliferation. The appearances were thus of localized nodular hyperplasia as seen in partial nodular transformation, together with relative atrophy of the remaining liver.

\section{Discussion}

Major anatomical anomalies of the liver, apart from the well recognized Riedel's lobe (Riedel, 1888 ), are unusual and are often only discovered incidentally at operation or post-mortem. Accessory lobes of the liver, if pedunculated, may become symptomatic if they undergo torsion and infarction (Omanik and Jablonsky, 1972; Pujari and Deodhare, 1976). Massive enlargement of the caudate lobe is, however, most unusual.

It is now recognized that disproportionate enlargement of the caudate lobe may occur in the Budd-Chiari syndrome (Tavill et al., 1975) and this may be apparent on hepatic scintiscanning with predominant central localization of radio colloid, and on inferior vena cavography which shows a characteristic antero-posterior narrowing. The separate venous drainage of the caudate lobe, directly into the transhepatic inferior vena cava, is usually preserved when the main hepatic veins are occluded $\overrightarrow{\vec{\overrightarrow{ }}}$ and hypertrophy of the caudate lobe occurs because 3 of its retained perfusion. In this case there was no evidence of hepatic vein thrombosis.

Benign tumours and tumour-like conditions may also affect the caudate lobe. Areas of focal nodular 3 . hyperplasia and hepatic adenomas may be $20 \mathrm{~cm}$ or more in diameter (Phillips et al., 1973; Gold, Guzman and Rosai, 1978). Lesions of focal nodularo hyperplasia have expanding margins but are not $₹$ encapsulated, and characteristically have a depressed음 central scar. Microscopically, the latter contains proliferating bile ducts. Similarly, hepatic cello adenomas have pushing margins and at most only a partial capsule but they differ from focal nodular ${ }^{\circ}$ hyperplasia in that they lack fibrosis and bile duct $\tilde{O}^{\circ}$ structures.

Most of these tumours present either as incidentalo findings or with localizing symptoms. However, ac

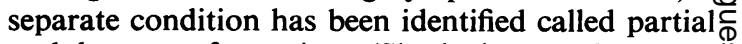
nodular transformation (Sherlock et al., 1966; $\stackrel{\text { ? }}{+}$ Classen et al., 1970; Dick and Gresham, 1972) which may cause portal hypertension. In this, the nodules appear to be relatively restricted to the $\stackrel{\mathbb{\Phi}}{\Phi}$ 
perihilar portion of the liver where they may cause extrinsic compression upon the hepatic vascular bed. Like the other tumours, this condition is observed almost exclusively in women of childbearing age. It has a somewhat variable histological appearance but has been clearly distinguished from both focal nodular hyperplasia and nodular regenerative hyperplasia (Sherlock et al., 1966). Nodular regenerative hyperplasia is a diffuse nodularity of the liver cells with no or only minimal fibrosis (Steiner, 1959). The condition was reviewed recently by Rougier et al. (1978) who found only 11 well documented previous cases and added 6 further cases of their own. Although all their own cases presented with portal hypertension this was found in only about $50 \%$ of those previously reported. However, in all cases it was a diffuse disease, apparently affecting all parts of the liver equally. Nevertheless, the changes seen in the caudate lobe in this case were histologically indistinguishable from nodular regenerative hyperplasia, but the main part of the liver was unaffected. The present case thus appears to be a localized form of nodular regenerative hyperplasia and is similar in this respect to the previously reported cases of partial nodular transformation. It is uncertain whether this condition is reactive, neoplastic or a malformation and the current case sheds little light upon this problem. Most of the previously reported cases have been in women of childbearing age and this is thus an exception in this respect. The most common predisposing conditions associated with the diffuse form of nodular regenerative hyperplasia are rheumatoid arthritis and congestive heart failure. There was no evidence of rheumatoid disease in this patient but, although there was little clinical evidence of congestive heart failure, there was centrilobular sinusoidal dilatation in the liver together with moderate cardiac enlargement $(470 \mathrm{~g})$ attributable to essential hypertension.

The main clinical feature in this case was the rapid development of ascites in a previously fit patient which caused severe abdominal pain and peritonism. This suggests that the portal vein thrombosis was the cause of the ascites and a recent event attributable to extrinsic compression by the enlarged caudate lobe. The absence of splenic enlargement and other signs of long-standing portal hypertension would support this. In contrast, in the previously reported cases of partial nodular transformation it was considered that a post-sinusoidal block was the probable mechanism of the long-standing portal hypertension (Sherlock et al., 1966; Classen et al., 1970).

The current case thus appears to be a unique example of partial nodular transformation of the liver in an elderly woman, which presented when it caused extrinsic pressure upon the portal vein.

\section{Acknowledgements}

We are grateful to Mr D. C. Dunn for permission to report the details of this case, and Miss S. Beasley and Miss S. Weedon for their secretarial help.

\section{References}

Classen, M., Elster, K., Pesch, H.J. \& Demling, L. (1970) Portal hypertension caused by partial nodular transformation of the liver. Gut, 11, 245.

Dick, A.P. \& GreshaM, G.A. (1972) Partial nodular transformation of the liver presenting with ascites. Gut, 13, 289.

Gold, J.H., Guzman, I.J. \& RosaI, J. (1978) Benign tumors of the liver. Pathological examination of 45 cases. American Journal of Clinical Pathology, 70, 6.

OMANIK, S. \& JABlonsky, I. (1972) Pedunculated accessory hepatic lobe. Archives of Surgery, 105, 792.

Phillips, M.J., Langer, B., Stone, R., Fisher, M.J. \& Ritchie, S. (1973) Benign liver cell tumors. Cancer. Philadelphia, 32, 463.

Pujari, B.D. \& Deodhare, S.G. (1976) Symptomatic accessory lobe of liver with a review of the literature. Postgraduate Medical Journal, 52, 234.

RIEDEL, I. (1888) Uber den zungenformigen Fortsatz des rechten Leberlappens und seine pathognostische Bedeutung für die Erkrankung der Gallenblase nebst Bemerkungen über Gallenstein operationem. Berliner klinischer Wochenschrift, 25, 577.

Rougier, P., Degott, C., RuefF, B. \& Benhamon, J.P. (1978) Nodular regenerative hyperplasia of the liver. Report of six cases and review of the literature. Gastroenterology, 75, 169.

Sherlock, S., Feldman, C.A., Moran, B. \& Scheuer, P.J. (1966) Partial nodular transformation of the liver with portal hypertension. American Journal of Medicine, 40, 195.

STEINER, P.E. (1959) Nodular regenerative hyperplasia of the liver. American Journal of Pathology, 35, 943.

TAvill, A.S., WoOd, E.J., Kreel, L., Jones, E.A., Gregory, M. \& Sherlock, S. (1975) The Budd-Chiari syndrome: correlation between hepatic scintigraphy and the clinical, radiological and pathological findings in nineteen cases of hepatic venous outflow obstruction. Gastroenterology, 68, 509.

Thompson, E.N. \& Sherlock, S. (1964) The etiology of portal vein thrombosis with particular reference to the role of infection and exchange transfusion. Quarterly Journal of Medicine, 33, 465.

Turcotte, J.G. \& ChILd, C.G. (1972) Idiopathic extrahepatic portal hypertension in adults. American Journal of Surgery, 123, 35. 